\title{
ESTADO INFLAMATÓRIO SUBCLÍNICO E BIOMARCADORES DE ALTERAÇÃO DO METABOLISMO GLICÍDICO EM ADOLESCENTES ESCOLARES
}

\author{
SUBCLINICAL INFLAMMATORY STATUS AND BIOMARKERS OF \\ ALTERATION OF GLYCIDIC METABOLISM IN SCHOOL TEENAGERS
}

\author{
Rafaela Ramos Dantas ${ }^{1}$ \\ Liliane de Almeida Cardoso ${ }^{2}$ \\ Danielle Figueiredo Patrício ${ }^{3}$ \\ Andrezza Oliveira Barros ${ }^{4}$ \\ Carla Campos Muniz Medeiros ${ }^{5}$
}

RESUMO: INTRODUÇÃO: A obesidade é uma das doenças crônicas não transmissíveis que mais avanças no Brasil e no mundo, tanto na infância como na adolescência. Trazendo consigo repercussões fisiológicas e metabólicas (dislipidemias e diabetes melittus tipo 2). OBJETIVO: Avaliar a relação do estado inflamatório subclínico e marcadores de alteração do metabolismo glicídico em adolescentes escolares. METODOLOGIA: Estudo transversal quantitativo, realizado entre setembro de 2012 a junho de 2013. A amostra foi composta por 194 adolescentes entre 15 e 19 anos. O estado inflamatório subclínico foi avaliado através da PCR-us; para diagnóstico da resistência insulínica foi utilizado o HOMAIR, cálculo do IMC. A análise estatística foi realizada no programa SPSS versão 22.0, descrição com medidas de tendência central, teste qui-quadrado e teste KrusKall -Wallis para comparar a mediana da PCR entre os grupos. RESULTADOS: Dos adolescentes avaliados, 15,4 \% tinham excesso de peso e 11,3\% alteração relação cintura/estatura. A PCR elevada esteve presente em 9,8\% dos adolescentes. O marcador da alteração do metabolismo glicídico mais frequente foi a RI presente em $14,9 \%$ da amostra. Não houve prevalência de hiperglicemia, e 5,1\% dos adolescentes apresentaram a hemoglobina glicada alterada. Entre os que tinham o PCR elevado, foi observada uma maior prevalência dos biomarcadores de alteração

\footnotetext{
${ }_{1}^{1}$ Doutoranda-Pós Graduação de Enfermagema UPE/UEPB, rafinha.dantas@hotmail.com.

Discente do Curso de Enfermagem da Universidade Estadual da Paraíba, almeida.lilianne@gmail.com.

${ }^{3}$ Mestre em Psicologia da Saúde. Docente do Departamento de Enfermagem da Universidade Estadual da Paraíba, dani.enfermagem8@gmail.com.

4 Enfermeira Assistencial Especialista em UTI e Urgência e Emergência, dezabarros@gmail.com.

5 Docente do Departamento de Enfermagem da Universidade Estadual da Paraíba, carlamunizmedeiros@hotmail.com.
} 
do metabolismo glicídico, com exceção da glicemia de jejum, porém não foi verificada associação entre essas condições. CONCLUSÃO: Estado inflamatório foi prevalente na amostra, evidenciando a fundamental importância na promoção da saúde e a prevenção de doenças já nas fases inicias da vida.

Palavras chave: Adolescentes; Diabetes Melittus; Inflamação; Resistencia à Insulina.

ABSTRACT: INTRODUCTION: Obesity is one of the most advanced noncommunicable chronic diseases in Brazil and worldwide, both in childhood and adolescence. Bringing physiological and metabolic repercussions (dyslipidemias and type 2 diabetes mellitus). Objective: To evaluate the relationship between subclinical inflammatory status and markers of altered glycemic metabolism in school adolescents. OBJECTIVE: To evaluate the relationship between subclinical inflammatory status and markers of altered glycemic metabolism in school adolescents. METHODOLOGY: Quantitative cross-sectional study, conducted from September 2012 to June 2013. The sample consisted of 194 adolescents between 15 and 19 years old. Subclinical inflammatory status was assessed by hs-CRP; To diagnose insulin resistance, the HOMA-IR was used to calculate BMI. Statistical analysis was performed using the SPSS version 22.0 software, description with central tendency measures, chi-square test and KrusKall-Wallis test to compare the CRP median between groups. RESULTS: Of the adolescents evaluated, $15.4 \%$ were overweight and $11.3 \%$ altered waist / height ratio. High CRP was present in $9.8 \%$ of adolescents. The most frequent marker of altered glycemic metabolism was IR present in $14.9 \%$ of the sample. There was no prevalence of hyperglycemia, and $5.1 \%$ of adolescents had altered glycated hemoglobin. Among those with high CRP, there was a higher prevalence of biomarkers of altered glucose metabolism, except for fasting glucose, but no association was found between these conditions. CONCLUSION: Inflammatory state was prevalent in the sample, highlighting the fundamental importance in health promotion and disease prevention in the early stages of life.

Keywords: Teens; Melittus diabetes; Inflammation; Insulin resistance. 


\section{INTRODUÇÃO}

A obesidade se apresenta como uma das doenças crônicas não transmissíveis (DCNT) que mais avança, tendo adquirido características epidêmicas, a nível mundial, tanto na infância como na adolescência (IBGE, 2010; SPRUIJTMETZ, 2011). No Brasil, tem sido observado um aumento na prevalência de obesidade na população infanto- juvenil (RODRIGUES, 2011; FERREIRA, 2012).

Esse cenário é preocupante, uma vez que a obesidade é um potente fator de risco para outras enfermidades, sendo responsável por sérias repercussões fisiológicas e metabólicas, interferindo na saúde infanto-juvenil e deixando sequelas para a vida adulta (FERREIRA, 2012).

O tecido adiposo é capaz de secretar várias adipocinas pró-inflamatórias, tendo, o fator de necrose tumoral-alfa (TNF- alfa), a interleucina (IL-6), a adiponectina e a leptina como as mais estudadas (MONTERO, 2012). Essas citocinas são liberadas quando o indivíduo encontra-se obeso, podendo apontar como o início de várias complicações para os indivíduos (TAM, 2010).

Uma das principais proteínas da fase aguda do estado inflamatório marcado pela presença dessas adipocinas é a Proteína C-Reativa (PCR), sintetizada no fígado em resposta a qualquer estímulo inflamatório (BISOENDIAL, 2009). É utilizada como um marcador de inflamação relacionada à obesidade, responsável por aumentar a IL-6 nos tecidos adiposos que são liberados na circulação sanguínea, e chega ao fígado de forma rápida, ativando o processo inflamatório subclínico (FRANCO, 2010).

A obesidade está associada a diferentes graus de inflamação sistêmica, evidenciada por diversos autores que demonstraram o aumento de marcadores plasmáticos pró-inflamatórios e aterogênicos em indivíduos obesos (CONROY, 2011). Como uma das consequências da obesidade, ocorrem as alterações no metabolismo glicídico, hiperinsulinismo, Resistencia a Insulina (RI) e hiperglicemia (WANG, 2011; MONTERO, 2012). A RI pode ser definida como um distúrbio 
metabólico, marcado por déficit na absorção da glicose em todo o organismo, ou seja, ocorre quando a capacidade da insulina em utilizar a glicose nos tecidos periféricos adiposos, hepáticos e musculares, encontra-se prejudicada (SIGWALT, 2014).

Segundo a Associação Americana de Diabetes (ADA, 2006), o Diabetes Mellitus conceitua-se como um agrupamento de transtornos metabólicos, que resultam em hiperglicemia crônica por consequência da diminuição da sensibilidade dos tecidos à ação da insulina e/ou da deficiência de sua secreção.

O Diabetes pode ser classificado em tipo 1 e tipo 2. No primeiro, ocorre uma deficiência na produção da insulina por destruição das células beta pancreáticas, de origem autoimune ou não, podendo atingir os jovens com instalação rápida ou em adultos com instalação insidiosa (CASSARINO - PEREZ, 2014).

No Diabetes tipo 2, há um aumento dos valores glicêmicos, e, inicialmente, o pâncreas produz insulina extra como mecanismo compensatório (Resistência à Insulina), porém, não se perdura, pois não é mais capaz de produzir insulina suficiente para manter a sua glicose no sangue em níveis normais por muito tempo (LIMA, 2014).

A associação entre a resistência insulínica e o estado inflamatório subclínico, definido pela PCR, é pouco elucidada na literatura atual, portanto, o objetivo desse estudo foi avaliar a associação entre o estado inflamatório subclínico, avaliado através da PCR ultra-sensível, e os biomarcadores de alteração do metabolismo glicídico em adolescentes de escola pública do município de Campina Grande/PB.

\section{METODOLOGIA}

Estudo transversal, com abordagem quantitativa, realizado a partir de um projeto maior intitulado: "Risco Cardiovascular pelo Pathobiological determinants of atherosclerosis in youth em adolescentes escolares da rede pública de ensino, Campina Grande", que foi aprovado pelo Comitê de Ética em Pesquisa (CEP) pela Universidade Estadual da Paraíba (CAEE: 0077.0.133.000-12), e desenvolvido no 
período de setembro de 2012 a junho de 2013, em escolas públicas estaduais do município de Campina Grande, Paraíba, Brasil.

A população-alvo foi composta por adolescentes de 15 a 19 anos, matriculados no ensino médio de escolas estaduais do município de Campina Grande- PB. A amostragem se deu por conglomerado em dois estágios. Inicialmente, foram selecionadas as escolas e, em seguida, as turmas. Assim, a turma foi considerada a unidade amostral.

Como critérios de inclusão têm-se a faixa etária entre 15 e 19 anos e estar regularmente matriculado na rede pública estadual do município de Campina Grande - PB. Foram excluídos aqueles que se apresentaram com as seguintes condições: síndromes genéticas, obesidade com hipertensão arterial secundária, gravidez, diabetes tipo 1, doença subjacente como insuficiência hepática e síndrome nefrótica, uso de medicação que interfira no metabolismo glicídico ou lipídico.

As variáveis do estudo foram classificadas em sócio-demográficas: sexo, cor da pele e escolaridade materna; bioquímicas: glicemia de jejum ( $\mathrm{mmol} / \mathrm{L})$, insulina de jejum $(\mu \mathrm{Ul} / \mathrm{mL})$, hemoglobina glicada (\%) PCR-us (mg/L) e HOMA, e antropométricas: peso $(\mathrm{Kg})$, altura $(\mathrm{m})$ e Índice de Massa Corporal (IMC) e relação cintura/estatura $(\mathrm{cm})$.

A amostra foi composta por 13 turmas, de 6 escolas. Da amostra inicial de 228 adolescentes, registraram-se oito exclusões pelo alto valor do PCR-us (valor igual ou superior a $10 \mathrm{mg} / \mathrm{L}$ ) pois o mesmo sugere processo infeccioso agudo. Houveram vinte e seis (26) perdas ao total, vinte e duas (22) por não possuírem nos exames laboratoriais a insulina basal, e cinco (04) por responder apenas parte dos questionários. A amostra foi, então, composta por 194 adolescentes, distribuídos quanto às exclusões e perdas entre as escolas sorteadas, conforme mostra a tabela a seguir (Tabela 1). 
TABELA 1 - Apresentação da amostra do estudo quanto às perdas e exclusões entre as escolas sorteadas.

\begin{tabular}{cccc}
\hline ESCOLAS & PERDAS & EXCLUSÃO & AMOSTRA FINAL \\
\hline A & 01 & 00 & 11 \\
B & 04 & 02 & 41 \\
C & 21 & 00 & 22 \\
D & 00 & 01 & 15 \\
E & 00 & 04 & 55 \\
F & 00 & 01 & 51 \\
& & TOTAL: & $\mathbf{1 9 4}$ \\
\hline
\end{tabular}

Através de um formulário semiestruturado foram obtidos dados como idade, sexo, e cor da pele, juntamente com as variáveis econômicas de acordo com os critérios da Associação Brasileira de Empresas de Pesquisa - ABEP (2008). Esses critérios é uma relação com o poder aquisitivo da família, expresso em termos de renda familiar, classificando os indivíduos pertencentes da classe $A$ até $E$, onde as classes $A$ e $B$ os indivíduos possuíam maiores rendas familiar média, de forma regressiva para as classes $C, D$ e $E$.

As amostras sanguíneas foram coletadas em dias agendados no período da manhã após 12 horas de jejum nas escolas por técnicos especializados e foram encaminhadas para um laboratório de Análises clínicas de referência, certificado com selo de qualidade Control Lab-Proficiência em Ensaios Laboratoriais (PELM). Para as análises bioquímicas, foram utilizados materiais descartáveis. As amostras de sangue, aproximadamente $10,0 \mathrm{ml}$, foram obtidas através de punção venosa, sendo analisadas em equipamento automático (Modelo BioSystems 310). Foram consideradas como marcadores de alteração do metabolismo glicídico a presença de glicemia, insulina, hemoglobina glicada A1c ou HOMA-IR elevados.

Como critério para diagnóstico da resistência insulínica, foi utilizado o índice HOMA-IR, que é o produto da insulina de jejum $(\mu U \mathrm{U} / \mathrm{mL})$ e da glicemia de jejum (mmol/L) dividido por 22,5. Como ponto de corte, foi utilizado HOMA-RI $\geq 2,5$. A Hemoglobina Glicada $(\mathrm{HbA} 1 \mathrm{C})$ reflete efetivamente a média de controle glicêmico dos últimos 2 a 4 meses. Para a insulina de jejum alterada $(\geq 15 \mu \mathrm{U} / \mathrm{mL})$, os pontos de corte para adolescentes foram os preconizados pela I Diretriz de Prevenção da Aterosclerose na Infância e na Adolescência. Foram consideradas como marcadores 
de alteração do metabolismo glicídico a presença de glicemia, insulina, hemoglobina glicada A1c ou HOMA-IR elevados.

As variáveis antropométricas, peso, altura e circunferência abdominal, foram mensuradas em duplicata, utilizando-se a média entre as medidas obtidas. Para a obtenção do peso utilizou-se uma balança digital Tanita ${ }^{\circledR}$ com capacidade para $150 \mathrm{~kg}$ e precisão de $0,1 \mathrm{~kg}$. A altura foi aferida através de um estadiômetro portátil da marca Tonelli ${ }^{\circledR}$ com precisão de $0,1 \mathrm{~cm}$. Durante a aferição, foram seguidos os procedimentos recomendados pela OMS (WHO, 1995). O Índice de Massa Corpórea (IMC) foi realizado a partir da razão do peso pelo quadrado da altura. Sendo aplicado para avaliação do estado nutricional. A categorização do estado nutricional considerou os seguintes pontos de corte, segundo o Escore-z de IMC-Idade para adolescentes de 10 a 18 anos: baixo peso ( $\geq$ Escore-z -3 e $<$ Escore-z -2 ), eutrofia ( $\geq$ Escore-z -2 e < Escore-z +1), sobrepeso ( $\geq$ Escore-z +1 e $<$ Escore- $z+2$ ), obesidade ( $\geq$ Escore-z +2 e $<$ Escore-z +3 ) e obesidade acentuada ( $\geq$ Escore-z +3 ). E os maiores de 18 anos: baixo peso $(<17,5)$, eutrofia $(\geq 17,5$ e $<25,0)$, sobrepeso $(\geq$ $25,0$ e $<30)$, obesidade $(\geq 30,0)(\mathrm{WHO}, 2007)$.

Logo após foram agrupados em duas categorias, sendo classificadas como eutróficos/baixo peso, e o grupo excesso de peso (sobrepeso e obesidade). A circunferência abdominal (CA) foi avaliada com fita métrica inelástica da marca Cardiomed $^{\circledR}$, com precisão de $0,1 \mathrm{~cm}$, no ponto médio entre a borda superior da crista ilíaca e o último rebordo costal, com o paciente em pé, sem roupa, com os braços posicionados ao longo do corpo e na fase expiratória da respiração. Como indicador antropométrico de obesidade abdominal, calculou-se a relação cintura/estatura (RCE) que foi obtida pelo quociente entre a circunferência da cintura $(\mathrm{cm})$ e a estatura $(\mathrm{cm})$, foi classificado alterada medidas $\geq 0,5$.

Foi realizada a descrição da amostra através das medidas de tendência central, frequência absoluta e relativa. Para a verificação da distribuição das variáveis de acordo com o sexo bem como o estudo da associação entre a presença de PCR us elevado com estado nutricional e com os indicadores de alteração do metabolismo glicídico foi realizado o teste de qui-quadrado. Para avaliação do valor da PCR- us em relação ao estado nutricional e a presença de RI, os adolescentes foram distribuídos em quatro grupos de acordo com o estado nutricional e a 
presença da RI (baixo peso/eutrofia sem RI, baixo peso/eutrofia com RI, sobrepeso/obesidade sem RI, sobrepeso/obesidade com RI), sendo utilizado a construção do blox-plot através do explore do programa SPSS. Após a verificação da distribuição assimétrica da variável PCR-us através do teste Kolmogorov Smirnov, foi utilizado o teste KrusKall -Wallis para comparar a mediana da PCR entre os grupos. A análise estatística foi realizada através do SPSS versão 22,0, e adotou-se um nível de significância de 5\%.

\section{RESULTADOS E DISCUSSÕES}

Houve uma maior proporção de adolescentes do sexo feminino (67,5\%), de cor não branca $(76,8 \%)$ e com idade entre 15 e 16 anos (60,8\%). Quanto à classe social, 58,8\% dos adolescentes pertenciam à classe econômica C, D e E, e a maioria $(67,5 \%)$ de suas mães e/ou responsáveis possuíam mais do que 8 anos de estudo (Tabela 1). Em relação ao estado nutricional e a relação cintura/estatura elevada (REC), foi observado que $11,3 \%$ dos adolescentes possuíam alteração com maior prevalência no sexo masculino. (Tabela 1). Quanto às variáveis bioquímicas, o PCR-us elevado esteve presente em 9,8\% dos escolares e a RI em 14,9\% sendo o marcador de alteração do metabolismo glicídico mais frequente. Apesar da prevalência de RI e PCR-us elevada ter sido maior no sexo feminino, não houve associação dessas duas variáveis com o sexo (Tabela 1). 
TABELA 1. Distribuição das variáveis de acordo com o sexo entre os adolescentes escolares de Campina Grande, Paraíba, Brasil, 2013.

\begin{tabular}{|c|c|c|c|c|}
\hline & & SEXO & & \\
\hline VARIÁVEL & TOTAL n(\%) & Feminino $\mathrm{n}(\%)$ & asculino $n(\%)$ & $\boldsymbol{P}$ \\
\hline $\begin{array}{c}\text { COR } \\
\text { Brancos } \\
\text { Não brancos }\end{array}$ & $\begin{array}{c}39(20,7) \\
149(79,3)\end{array}$ & $\begin{array}{c}24(19,0) \\
102(81,0)\end{array}$ & $\begin{array}{l}15(24,2) \\
47(75,8)\end{array}$ & 0,413 \\
\hline $\begin{array}{c}\text { IDADE } \\
15-16 \text { anos } \\
17-19 \text { anos }\end{array}$ & $\begin{array}{l}118(60,8) \\
76(39,2)\end{array}$ & $\begin{array}{l}86(65,6) \\
45(34,4)\end{array}$ & $\begin{array}{l}32(50,8) \\
31(49,2)\end{array}$ & 0,047 \\
\hline $\begin{array}{c}\text { CLASSE SOCIAL } \\
A \text { e } B \\
C, D \text { e } E\end{array}$ & $\begin{array}{c}80(41,2) \\
114(58,8)\end{array}$ & $\begin{array}{l}53(40,5) \\
78(59,5)\end{array}$ & $\begin{array}{l}27(42,9) \\
36(57,1)\end{array}$ & 0,751 \\
\hline $\begin{array}{c}\text { ESCOLARIDADE } \\
\text { MATERNA } \\
\leq 8 \text { anos de estudo } \\
>8 \text { anos de estudos }\end{array}$ & $\begin{array}{l}61(31,8) \\
131(68,2)\end{array}$ & $\begin{array}{l}42(32,6) \\
87(67,4)\end{array}$ & $\begin{array}{l}19(30,2) \\
44(69,8)\end{array}$ & 0,737 \\
\hline $\begin{array}{c}\text { GLICEMIA } \\
\text { Normal } \\
\text { Alterada }\end{array}$ & $\begin{array}{c}194(100 \%) \\
00(00)\end{array}$ & $\begin{array}{c}132(67,9) \\
00(00)\end{array}$ & $\begin{array}{c}62(32,1) \\
00(00)\end{array}$ & - \\
\hline $\begin{array}{c}\text { HOMA Normal } \\
\text { Alterada }\end{array}$ & $\begin{array}{c}165(85,1) \\
29(14,9)\end{array}$ & $\begin{array}{l}109(83,2) \\
22(16,8)\end{array}$ & $\begin{array}{l}56(88,9) \\
07(11,1)\end{array}$ & 0,299 \\
\hline $\begin{array}{c}\text { INSULINA } \\
\text { Normal Alterado }\end{array}$ & $\begin{array}{c}178(92,2) \\
15(7,8)\end{array}$ & $\begin{array}{c}119(90,8) \\
12(9,2)\end{array}$ & $\begin{array}{c}59(92,5) \\
03(4,8)\end{array}$ & 0,394 \\
\hline $\begin{array}{l}\text { PCR - ultrassensível } \\
\text { Normal Alterada }\end{array}$ & $\begin{array}{c}175(90,2) \\
19(9,8)\end{array}$ & $\begin{array}{l}115(87,8) \\
16(12,2)\end{array}$ & $\begin{array}{c}60(95,2) \\
03(4,8)\end{array}$ & 0,102 \\
\hline $\begin{array}{l}\text { HEMOGLOBINA } \\
\text { GLICADA } \\
\text { Normal Alterada }\end{array}$ & $\begin{array}{c}184(94,9) \\
10(5,1)\end{array}$ & $\begin{array}{c}123(93,9) \\
08(6,1)\end{array}$ & $61(96,8)$ & 0,504 \\
\hline $\begin{array}{c}\text { ESTADO } \\
\text { NUTRICIONAL } \\
\text { Baixo Peso/ Eutrófico } \\
\text { Excesso de Peso }\end{array}$ & $\begin{array}{l}164(84,5) \\
30(15,5)\end{array}$ & $\begin{array}{c}113(86,3) \\
18(13,7)\end{array}$ & $\begin{array}{l}51(81,0) \\
12(19,0)\end{array}$ & 0,338 \\
\hline $\begin{array}{c}\text { RCE } \\
\text { Normal Alterada }\end{array}$ & $\begin{array}{c}172(88,7) \\
22(11,3)\end{array}$ & $\begin{array}{c}117(89,3) \\
14(10,7)\end{array}$ & $\begin{array}{l}55(87,3) \\
08(12,7)\end{array}$ & 0,863 \\
\hline
\end{tabular}

A PCR us elevada esteve associada à cor não branca $(p=0,026)$, ao excesso de peso $(p=0,017)$ e a relação cintura/estatura elevada $(p=0,011)$. Apesar da prevalência de PCR elevado ter sido maior entre os adolescentes com os indicadores de alteração do metabolismo glicídico presente, não foi verificada associação da PCR elevada com a HbA1c, insulina e HOMA-IR alterados (Tabela 2). 
TABELA2. Distribuição das variáveis de acordo com a PCR-us entre os adolescentes escolares de Campina Grande, Paraíba, Brasil, 2013.

\begin{tabular}{|c|c|c|c|c|}
\hline \multirow[b]{2}{*}{ VARIÁVEL } & \multirow[b]{2}{*}{ TOTAL n(\%) } & \multicolumn{2}{|l|}{ PCR-us } & \multirow[b]{2}{*}{$P$} \\
\hline & & Alto Risco N (\%) & Baixo Risco n (\%) & \\
\hline $\begin{array}{l}\text { IDADE } \\
15 \text { - } 16 \text { anos } \\
17 \text { - } 19 \text { anos }\end{array}$ & $\begin{array}{l}118(60,8) \\
76(39,2)\end{array}$ & $\begin{array}{c}08(6,8) \\
11(14,5)\end{array}$ & $\begin{array}{c}110(93,2) \\
65(85,5)\end{array}$ & 0,078 \\
\hline $\begin{array}{l}\text { COR } \\
\text { Brancos } \\
\text { Não Brancos }\end{array}$ & $\begin{array}{c}39(20,1) \\
149(76,8)\end{array}$ & $\begin{array}{c}00(0) \\
17(11,4)\end{array}$ & $\begin{array}{c}39(100) \\
132(88,6)\end{array}$ & 0,026 \\
\hline $\begin{array}{l}\text { HOMA } \\
\text { Normal Alterado }\end{array}$ & $\begin{array}{c}165(85,1) \\
29(14,9)\end{array}$ & $\begin{array}{l}14(8,5) \\
5(17,2)\end{array}$ & $\begin{array}{l}151(91,5) \\
24(82,8)\end{array}$ & 0,261 \\
\hline $\begin{array}{l}\text { INSULINA } \\
\text { Normal Alterado }\end{array}$ & $\begin{array}{c}178(92,2) \\
15(7,8)\end{array}$ & $\begin{array}{l}16(9,0) \\
03(20)\end{array}$ & $\begin{array}{c}162(91) \\
12(80)\end{array}$ & 0,171 \\
\hline $\begin{array}{l}\text { HBA1C } \\
\text { Normal Alterado }\end{array}$ & $\begin{array}{c}184(94,9) \\
10(5,1)\end{array}$ & $\begin{array}{c}17(9,2) \\
2(20)\end{array}$ & $\begin{array}{c}167(90,8) \\
08(80)\end{array}$ & 0,255 \\
\hline $\begin{array}{l}\text { ESTADO } \\
\text { NUTRICIONAL } \\
\text { Baixo Peso/ Eutrófico } \\
\text { Excesso de Peso }\end{array}$ & $\begin{array}{c}164(84,5) \\
30(15,5)\end{array}$ & $\begin{array}{c}12(7,3) \\
07(23,3)\end{array}$ & $\begin{array}{c}152(92,7) \\
23(76,7)\end{array}$ & 0,017 \\
\hline $\begin{array}{l}\text { RELAÇAO } \\
\text { CC/ESTATURA } \\
\text { Normal Alterado }\end{array}$ & $\begin{array}{c}172(88,7) \\
22(11,3)\end{array}$ & $\begin{array}{c}13(7,6) \\
06(27,3)\end{array}$ & $\begin{array}{c}159(92,4) \\
16(72,7) \\
\end{array}$ & 0,011 \\
\hline
\end{tabular}

Quando o estado nutricional foi estratificado pelo sexo, observou-se a associação da presença de sobrepeso/obesidade com a PCR us elevada no sexo feminino ( $p=0,010)$ (Tabela 3).

TABELA 3. Distribuição do estado nutricional e sexo de acordo com a PCR-us entre os adolescentes escolares de Campina Grande, Paraíba, Brasil, 2013.

\begin{tabular}{lcccc}
\hline & \multicolumn{3}{c}{ PCR-us } \\
& TOTAL n(\%) & Alto Risco n (\%) & Baixo Risco n (\%) & $P$ \\
$\begin{array}{l}\text { SEXo } \\
\text { Masculino }\end{array}$ & & & & \\
Baixo Peso/ Eutróficos & $51(81,0)$ & $02(3,9)$ & $19(96,1)$ & \\
$\begin{array}{l}\text { Excesso de Peso } \\
\text { Feminino }\end{array}$ & $12(19,0)$ & $01(8,3)$ & $11(91,7)$ & 0,476 \\
Baixo Peso/ Eutróficos & $113(86,3)$ & $10(8,8)$ & $103(91,2)$ & \\
Excesso de Peso & $18(13,7)$ & $06(33,3)$ & $12(66,7)$ & $\mathbf{0 , 0 1 0}$ \\
\hline
\end{tabular}


O gráfico Box-plot, abaixo, mostra a mediana de PCR-US de acordo com os grupos de estado nutricional. Assim, foi verificado que a mediana da PCR-us no grupo 3, indivíduos com obesidade sem Rl, encontra-se superior aos outros grupos. A presença de sobrepeso/obesidade foi mais importante a associação de uma maior mediana do que a presença de RI (Figura 1).

FIGURA 1- Distribuição das medianas de PCR-us de acordo com o estado nutricional entre os adolescentes escolares de Campina Grande, Paraíba, Brasil, 2013.

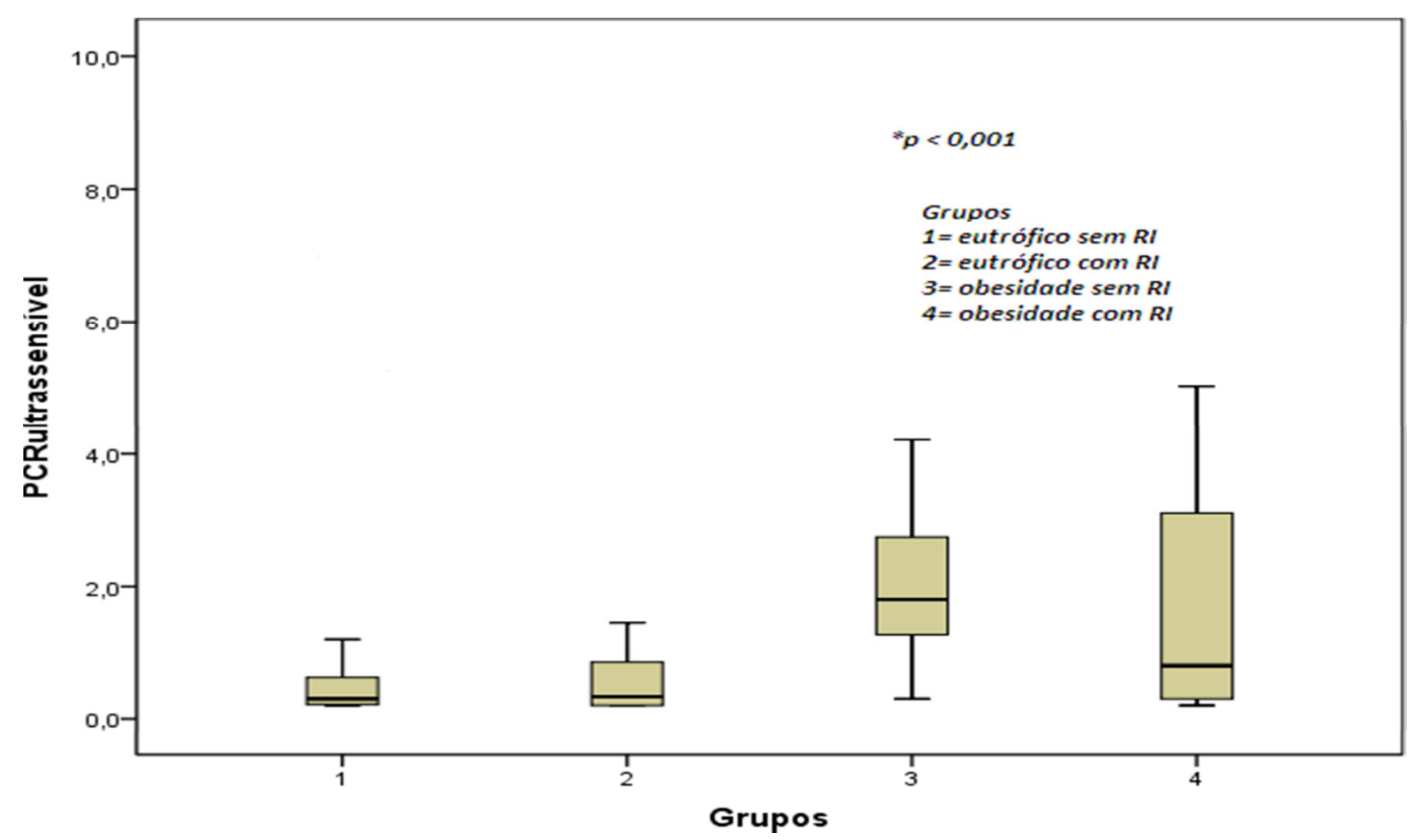

$R I=$ resistência insulínica. Grupo 1 (mediana $=0,3$; intervalo interquartílico $(I Q)=0,4$ ), Grupo 2 (mediana=0,3; IQ =0,7); Grupo 3 (mediana 1,$8 ; \mathrm{IQ}=1,7$ ), grupo 4 (mediana=0,79; $\mathrm{IQ}=1,1$ ) * $p<0,001$ (grupo 1 versus grupo 3; grupo1 versus grupo 4, grupo 2 versus grupo $3, p=0,001$ (grupo 3 versus grupo 4).

Observou-se que 9,8\% dos adolescentes apresentaram PCR-us elevado, configurando um estado inflamatório subclínico, com maior predominância no sexo feminino. Semelhante ao estudo de Rosini et al (2015) que 9,2\% dos adolescentes 
encontravam-se em estado inflamatório, porém, com maior prevalência no sexo masculino.

Essa diferença observada entre os valores, pode ser justificada pelas diversas faixas etárias e pontos de cortes utilizados pelos autores, além da literatura dispor de informações limitadas acerca da relação do processo inflamatório indicado pela PCR-us na população infanto-juvenil (CAMPANA, 2014; MIRAGLIA, 2012). Além disso, no Brasil há poucos estudos envolvendo essa proteína e adolescentes.

No presente estudo mais de $15 \%$ de escolares apresentaram excesso de peso, e essa condição esteve associada ao PCR-us elevado. Esse achado, foi observado em Campana (2014) que avaliou os adolescentes com excesso de peso na cidade do Rio de Janeiro, apresentando associação significativa entre os níveis de PCR-us e IMC. Quando estratificado, por sexo, o estado nutricional, o excesso de peso apresentou associação com o PCR- us elevada, apenas no sexo feminino.

No presente estudo, 33,3\% das meninas consideradas com excesso de peso, possuíam o PCR-us classificadas em estado de inflamação. O estudo de Rosini (2015) mostrou que $24 \%$ dos adolescentes encontravam-se com a RCE alterada, e sendo estatisticamente superior nas meninas. Os valores distintos podem ser justificados pelas diversas formas de se mensurar a circunferência abdominal, medida antropométrica que se utiliza para calcular relação cintura/estatura (FARIA, 2013).

Considerando que a RI seja um estágio que antecede o DM2 e que seja caracterizada devido à diminuição na capacidade da insulina em estimular a utilização da glicose (SANCHES, 2012), o diagnóstico precoce é de suma importância para que haja intervenções no âmbito da saúde pública. A determinação da RI neste estudo, foi feita pelo índice HOMA-IR, que vem sendo cada vez mais utilizado por sua forte correlação com o clamp euglicêmico hiperinsulinêmico (considerado padrão ouro). Além disso, o mesmo possui relativamente baixo custo e altos valores de correlação.

Dentre os escolares avaliados, aproximadamente 15\% foram diagnosticados com RI, valor superior ao estudo de Moreira et al (2014) que detectaram 7\% de RI em 45 adolescentes do município de Roncador- PR, com um ponto de corte do HOMA-RI superior a este estudo. Uma investigação realizada por Medeiros (2011), 
no município de Campina Grande, ao avaliar crianças e adolescentes obesos acompanhados por um ambulatório de referência foi encontrada uma prevalência de $41,3 \%$ de RI na população estudada e sua presença esteve associada com a faixa etária de 10 a 18 anos e à obesidade.

No presente estudo não foi encontrada associação entre o HOMA e o PCR-us (estado inflamatório), contrapondo os estudos de Oliveira (2014) e Lima (2014) que encontraram associação entre essas variáveis. Além disso, há evidencias que a RI é decorrente da obesidade e os mecanismos pelos quais, citocinas inflamatórias e ácidos graxos desencadeiam esta condição ainda não estão totalmente esclarecidos, podendo colocar a obesidade representando o ponto central entre a reação inflamatória, o diagnóstico de RI, e a ocorrências de doenças crônicas precocemente (HONORATO, 2010).

Nenhum dos adolescentes do estudo apresentou valores de glicemia de jejum alterada, porém, quanto à insulina, foi verificada que $7,7 \%$ tinham hiperinsulinemia semelhante ao estudo de Rosini (2015) e de Faria (2014) que ao avaliar os adolescentes do município de Guabiruba-SC e Viçosa - MG, verificaram 7,2\% e 9\%, respectivamente, tinham insulina elevada. E inferior ao estudo de Rigon (2013) que verificou entre os adolescentes uma prevalência de 19,5\% de hiperinsulinemia. Vale lembrar que todos os estudos citados acima possuíam o mesmo ponto de corte deste estudo, e com adolescentes eutróficos, porém com faixas etárias divergentes.

O hiperinsulinemismo é considerado um fator de risco independente para DCV, uma vez que desempenha importante papel no desenvolvimento de outros componentes para a Síndrome Metabólica (CASSANI, 2013). Embora os valores de glicemia de jejum estejam dentro da normalidade neste estudo, a presença dessa hiperinsulinemia parece estar refletindo uma maior atividade pancreática para manter a glicose dentro dos parâmetros normais. Oliveira (2014) mostrou associação significante entre os valores de insulina e PCR-us entre as adolescentes de 13-17 anos, diferentemente deste estudo que não constatou nenhuma diferença não só entre os sexos, mas também em associação entre essas variáveis.

Por este estudo ser do tipo transversal não há a possibilidade de aprofundamento para acompanhar e avaliar os adolescentes e nem de identificação da causalidade, além disso, a amostra da pesquisa pode se considerar insuficiente 
para constatar associação significativa em algumas variáveis. Outra limitação do estudo, é de não haver consenso na literatura da maioria dos pontos de cortes das referidas variáveis, podendo ser superestimada ou não. Porém, apesar dessas limitações, o estudo demonstra-se importante em âmbito da saúde pública, pois poucos estudos nacionais investigaram a relação das variáveis descritas no estudo, e com essa faixa etária juvenil, oportunizando diagnóstico precoce dos fatores de riscos para doenças cardiometabólicas, e prevenindo futuros agravos decorrentes da resistência insulínica e obesidade.

\section{CONSIDERAÇÕES FINAIS}

O estado inflamatório subcliníco foi prevalente entre os adolescentes estudados, apresentando associação significante com o estado nutricional e com a relação cintura/estatura. E, apesar de não ter sido encontrada associação entre os marcadores da alteração do metabolismo glicídico e a PCR-us elevada, a prevalência dessa alteração foi maior no grupo com evidência de inflamação subclínica.

Desta forma, evidencia-se que é de fundamental importância a promoção da saúde e a prevenção de doenças crônicas já nas fases inicias da vida, incluindo, nesta perspectiva, a reorientação dos hábitos alimentares, a prática regular de atividade física, além da detecção precoce de estado inflamatório subclínico e de alterações no metabolismo glicídico. Ademais, o ambiente escolar pode ser entendido como um espaço que possibilitaria essa intervenção. 


\section{REFERÊNCIAS BIBLIOGRÁFICAS}

BISOENDIAL, R. J. et al. C-reactive protein elicits white blood cell activation in humans. The American journal of medicine. v. 122, n. 6, p. 582. e1-582. e9, 2009.

CAMPANA, E. M. et al. Pressão arterial na adolescência, adipocinas e inflamação no adulto jovem. Estudo do Rio de Janeiro. Arquivos Brasileiros de Cardiologia. v. 102, n. 1, p. 60-9, 2014.

CASSANI, R. S. L et al. Ingestão de fibra alimentar e sua relação com resistência à insulina e os componentes da síndrome metabólica em adolescentes-brazilian metabolic syndrome study (brams). Sociedade Brasileira de Alimentação e Nutrição. v. 38, n. Sup. p. 259-259, 2013. CASSARINO-PEREZ, L; ALVES, C. F; DELL'AGLIO, D. D. Suporte social em adolescentes com Diabete Melito Tipo I: uma revisão sistemática. Revista da SPAGESP. v. 15, n. 1, p. 33-48, 2014.

CONROY, T. et al. FOLFIRINOX versus gemcitabine for metastatic pancreatic cancer. New England Journal of Medicine. v. 364, n. 19, p. 1817-1825, 2011.

COSTA, F. F; BENEDET, J; LEAL, D. B; ASSIS, M. A. A. Agregação de fatores de risco para doenças e agravos crônicos não transmissíveis em adultos de Florianópolis, SC. Revista Brasileira de Epidemiologia. v. 16, n. 2, p. 398-408, 2013.

Diretrizes da Sociedade Brasileira de Diabetes Tratamento e acompanhamento do diabetes mellitus. Sociedade Brasileira de Diabetes; 2007. Disponível em: http://www.diabetes.org.br. Acesso em: 14/04/2015.

FARIA, E. R. et al. Associação de diferentes medidas e índices antropométricos na predição de fatores de risco cardiovascular em adolescentes. Arquivos Brasileiros de Cardiologia. v. 38, n. 4, p. 82-82, 2013.

FERREIRA, J. S; AYDO, R. D. Adiposidade corporal e hipertensão arterial em crianças e adolescentes obesos. Revista Brasileira em Promoção da Saúde. v.22, n.2, p. 88-93, 2012.

FRANCO, R. R. Marcadores inflamatórios e infecciosos em pacientes com síndrome metabólica. Tese de Doutorado. Porto Alegre, 2010.

LIMA, A. C. S. et al. Fatores de risco para diabetes mellitus tipo 2 em universitários: associação com variáveis sociodemográficas. Revista Latino-Americana de Enfermagem. v. 22, n. 3, p. 484-490, 2014.

MEDEIROS, C. C. M. et al. Resistência insulínica e sua relação com os componentes da síndrome metabólica. Arquivos Brasileiros de Cardiologia. v. 97, n. 5, p. 380-389, 2011.

Ministério da Saúde (BR). Secretaria de Atenção à Saúde. Estratégias para o cuidado da pessoa com doença crônica: diabetes mellitus. Brasília (DF): Departamento de Atenção Básica; 2013.

MIRAGLIA, F; MELLO, E. D. Como avaliar o processo inflamatório em crianças com excesso de peso? Revista HCPA. v. 32, n. 3, p. 332-339, 2012.

MONTERO, D. et al. Endothelial dysfunction, inflammation, and oxidative stress in obese children and adolescents: markers and effect of lifestyle intervention. Obesity Reviews. v. 13, n. 5, p. 441-455, 2012.

MOREIRA, M. H; GIROLDO, M; BROETTO-BIAZON, A. C. Índice HOMA em Adolescentes com

Revista Interdisciplinar em Saúde, Cajazeiras, 7 (único): 190-205, 2020, ISSN: 2358-7490. 
Fatores de Risco Cardiovasculares/HomeostasisModelAssessment (HOMA) Index in AdolescentsWith Cardiovascular RiskFactors. Saúde e Pesquisa, v. 7, n. 3, 2014.

OLIVEIRA, N. A. P. et al. Prevalência de alguns fatores de risco para doenças crônicas não transmissíveis em adultos residentes no município de Alta Floresta. Revista Sociedade Brasileira de Alimentação e Nutrição. v. 39, n. 1, 2014.

RIGON, M. Z. P. The nutritional profile, glycemia, insulin resistance and Insul-tance from children and adolescents "Balance Food Project" in Santa Maria- RS. IJNutrology. v. 6, n. 2, 2013.

RODRIGUES, P. A. et al. Prevalência e fatores associados a sobrepeso e obesidade em escolares da rede pública. Ciência e Saúde coletiva. v. 16, n. suppl 1, p. 1581-8, 2011.

ROSINI, N. et al. Multiplicidade de Fatores de Risco Cardiovascular em Crianças e Adolescentes de Guabiruba-SC, Brasil. Revista de Saúde Pública de Santa Catarina. v. 7, n. 3, p. 33-45, 2015.

SANCHES, P. L. et al. Resistência insulínica pode prejudicar a redução da espessura mediointimal em adolescentes obesos. Arquivos Brasileiros de Cardiologia. v. 99, n. 4, p. 892899, 2012.

SIGWALTI, Fabia Rosa; DA SILVAI, Roseane Carla Rosendo. Resistência à insulina em adolescentes com e sem excesso de peso de município da Grande Florianópolis-SC. Ver Bras Enferm, v.67, n.1, p. 43-7, 2014.

SILVA, H. A. et al. Perfis antropométrico, lipídico e glicêmico em adolescentes de uma instituição filantrópica no noroeste do Paraná. Jornal Brasileiro de Patologia e Medicina Laboratorial. v. 46 , n. 1, p. 7-15, 2010

SPRUIJT-METZ, D. Etiology, treatment, and prevention of obesity in childhood and adolescence: A decade in review. Journal of research on Adolescence. v. 21, n. 1, p. 129152, 2011.

TAM, C. S. et al. IL-6, IL-8 and IL-10 levels in healthyweightandoverweightchildren. Hormoneresearch in paediatrics. v. 73, n. 2, p. 128- 134, 2010.

WANG, T. J. et al. Metabolite profiles andtheriskofdeveloping diabetes. Nature medicine. v. 17, n. 4, p. 448-453, 2011.

WORLD HEALTH ORGANIZATION - WHO. Physical Status: the study and interpretation of anthropometry. WHO Technical Report Series, n. 854. Geneva: WHO, 1995. 